\title{
Optics and phylogeny: is there an insight? The evolution of superposition eyes in the Decapoda (Crustacea)
}

\author{
Edward Gaten \\ Department of Biology, University of Leicester, Leicester LE1 7RH, U.K. E-mail: gat@leicester.ac.uk
}

Keywords: Compound eyes, superposition optics, adaptation, evolution, decapod crustaceans, phylogeny

\begin{abstract}
This paper addresses the use of eye structure and optics in the construction of crustacean phylogenies and presents an hypothesis for the evolution of superposition eyes in the Decapoda, based on the distribution of eye types in extant decapod families. It is suggested that reflecting superposition optics are symplesiomorphic for the Decapoda, having evolved only once, probably in the Devonian. Subsequent loss of reflecting superposition optics has occurred following the adoption of a new habitat (e.g. Aristeidae, Aeglidae) or by progenetic paedomorphosis (Paguroidea, Eubrachyura).
\end{abstract}

\section{Introduction}

The compound eye is one of the most complex and remarkable organs, not only on account of its optical precision, but also for the diversity of optical arrangements that have evolved. This is particularly true of the Crustacea, which includes examples of nine out of the ten described types of compound eye (Nilsson, 1989). Such is the complexity of the optics of most compound eyes, it is likely that once one had evolved, it would not be replaced by another unless the latter bestowed a significant optical advantage. It is for this reason that Land (1981) suggested that eye structure should be considered a conservative character.

Given these facts, it might be expected that the functional morphology of the compound eye would be considered by anyone interested in the classification and phylogeny of the Crustacea. However, this is not the case for a number of reasons. Most important from a practical point of view is that the optics used by a compound eye cannot normally be predicted by external examination alone, and usually microscopic investigation of properly fixed optical elements is required for a completê diagnosis. This largely rules out the use of fossil material in the comparatively few arthropodan specimens where the eyes are preserved (Glaessner, 1969), although the optics of some species of trilobite have been described (Clarkson \& Levi-Setti, 1975). Also the requirement for good fixation and the fact that complete examination invariably involves the destruction of the specimen means that museum collections rarely reveal enough information to define the optics unequivocally. Where the optics of the component parts of the eye are under investigation, specialised fixation to preserve the refractive properties must be used (Gaten, 1994).

.However, it is perhaps the response of the eye to adaptive pressures, resulting in convergence, that limits its usefulness in systematics. Particularly in those habitats where the effectiveness of the eye is lessened, such as in deep-sea, cavedwelling or burrowing crustaceans, the secondary reduction or loss of the eyes that usually occurs is unhelpful and often misleading. This leaves us with those animals bearing highly-evolved eyes that may be useful in discussing evolutionary relationships. Where similar advanced optics are used by different groups of animals, it is tempting to assume that they are synapomorphies unless there are compelling reasons to think otherwise. This is not always true, and even at the phylum level, similarities in eye structure may not always be indicative of the phylogeny of the animals 
under consideration. The presence in both crustaceans and insects of a compound eye containing the same basic structure has been considered one of the most serious problems to anyone maintaining the separate origins of these groups (Tiegs \& Manton, 1958). If they are not monophyletic, it is necessary to explain this phenomenon as extremely detailed convergence of the eyes of the crustacean and insect/myriapod groups.

In spite of such problems there may be a role for the study of physiological optics in the construction of decapod phylogenies. Even though the use of modern techniques, such as molecular biology, numerical taxonomy, and cladistic analysis has increased in recent years, functional morphological descriptions remain the principal tool of the systematist.

\section{Crustacean compound eyes}

Compound eyes are present in all crustacean classes except Copepoda, and moveable stalked eyes are present in the Malacostraca. In most cases, these eyes are of the apposition type in which the dioptric apparatus (corneal lens and crystalline cone) are in contact with the light-sensitive rhabdom (Fig. 1A). In this type of eye, light remains within a single ommatidium, passing from the corneal facet to the underlying rhabdom; this results in reasonably high resolution but low sensitivity. In the superposition eye (Fig. 1B) the dioptric apparatus and the rhabdom layer are separated by an unpigmented clear zone. This permits, in theory, the superposition of light from a number of corneal facets (up to 3000 in $\mathrm{Ne}$ phrops norvegicus - Gaten, 1988) onto a single rhabdom, although in practice the superposition focus covers several rhabdoms as a result of optical aberrations. Even though the more peripheral of these facets contribute less light to the image than the central ones, there is still an increase in sensitivity of between 10 and 1000 times over that of an apposition eye. This confers a considerable advantage in low-light habitats, although there is not, necessarily, any concomitant reduction in the resolution of which the eye is capable ( $\mathrm{Land}$, 1984).
The main feature of the superposition eye is that within the crystalline cone the light must be redirected across the optical axis of the ommatidium (Figs. 1C, E, G) to focus onto the target rhabdom. The different types of superposition eye are defined by the way in which this redirection of light occurs. The simplest way is by direct reflection of incident rays at the wall of the crystalline cone (Fig. 1C); this is the mechanism used in reflecting superposition eyes (Vogt, 1975; Land, 1976). It has been shown (Vogt, 1977) that focusing in this type of eye only works if the crystalline cones are square in cross section. Reflection within such a "mirror box" redirects light across the optical axis, as can be seen when the cone is viewed from above (Fig. 1D). A more complex mechanism for redirecting light is seen in the refracting superposition eye (Exner, 1891) which utilises a continuous gradient of refractive index within the cone (Figs. 1E, F). The third mechanism, termed parabolic superposition (Nilsson, 1988) uses a powerful corneal lens, a cylindrical lens within the crystalline cone, and a parabolic reflecting surface at the cone wall (Figs. 1G, H). Some xanthid crabs achieve the same effect using a crystalline cone with a square cross-section, rather than a cylindrical lens. A complete description of the optical mechanisms involved can be found in Nilsson (1989).

The identification of the optics being used by any specimen is rarely straightforward, with the appearance of the corneal facetting the only external evidence of optical type that can usually be seen. The most efficient way of packing cylindrical ommatidia into a hemispherical eye is by using an hexagonal array; in this way the angular separation of the ommatidia is reduced to a minimum and the resolution of the eye maximised. This is the situation used in apposition, refracting superposition and parabolic superposition eyes. Where a square crystalline cone is used, as in reflecting superposition eyes and some parabolic superposition eyes (Nilsson, 1988), a square packing array will give optimum resolution. Placing too much reliance on the external appearance of the cornea can lead to problems. For many years it was assumed that all eubrachyuran crabs used apposition optics as they possessed small, 

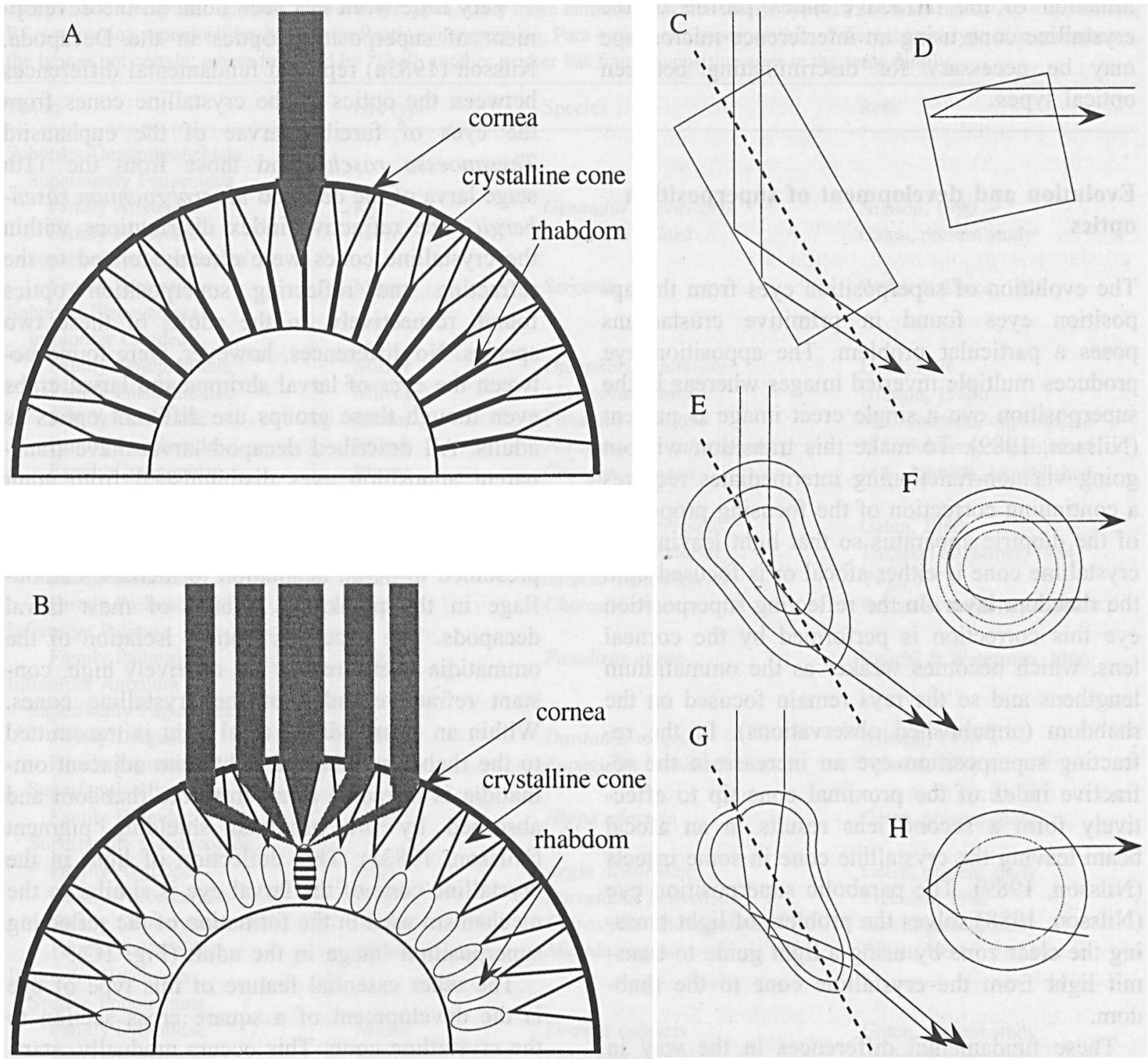

Fig. 1. Diagrammatic representation of the main types of crustacean compound eye: A, apposition eye, showing isolation of the ommatidium; B, superposition eye, showing redirection of light from many facets to the target rhabdom; $\mathrm{C}-\mathrm{H}$, light path through the crystalline cones of superposition eyes viewed from the side and from above (the dotted line marks the ommatidial axis); C, D, reflecting superposition; E, F, refracting superposition; G, H, parabolic superposition. After Nilsson, 1990 (not to scale).

hexagonally-faceted eyes. This was not corrected until the optics of the parabolic superposition eye were correctly described (Nilsson, 1988).

In live specimens the presence of an eyeshine patch covering several facets, caused by a tapetal reflection from within the eye, confirms that superposition optics are in use (Kunze, 1979). Care must be taken when using the absence of eyeshine to confirm the optics as in many species the eyeshine disappears when the eye is exposed to light and may also vary according to the direction of observation (Exner, 1891; Shelton et al., 1992; Gaten, 1994). Further identification of optical type requires that the eye be hemisected to show the clear zone in superposition eyes or that the component parts of the eye are examined microscopically. Some information can be obtained from the shape of the crystalline cone, but deter- 
mination of the refractive index profile of the crystalline cone using an interference microscope may be necessary for discriminating between optical types.

\section{Evolution and development of superposition optics}

The evolution of superposition eyes from the apposition eyes found in primitive crustaceans poses a particular problem. The apposition eye produces multiple inverted images whereas in the superposition eye a single erect image is present (Nilsson, 1989). To make this transition without going via non-functioning intermediates requires a continuing correction of the focusing properties of the dioptric apparatus so that light leaving the crystalline cone is either afocal or is focused onto the rhabdom layer. In the reflecting superposition eye this correction is performed by the corneal lens, which becomes weaker as the ommatidium lengthens and so the rays remain focused on the rhabdom (unpublished observations). In the refracting superposition eye an increase in the refractive index of the proximal cone tip to effectively form a second lens results in an afocal beam leaving the crystalline cone in some insects (Nilsson, 1989). The parabolic superposition eye (Nilsson, 1988) solves the problem of light crossing the clear zone by using a light guide to transmit light from the crystalline cone to the rhabdom.

These fundamental differences in the way in which this change from apposition to the different forms of superposition optics occurs means that the latter are not always interchangeable. It appears to be theoretically possible to transform the cylindrical lens of the parabolic superposition eye into the continuous lens cylinder of the refracting superposition eye (Nilsson, 1990). As various intermediates between the two types have been found it is very likely that evolution of one type from the other has occurred. In the case of the reflecting superposition eye, however, there is no apparent mechanism whereby the optics used could have evolved from either of the other types of superposition eye.
Very little work has been done on the development of superposition optics in the Decapoda. Nilsson (1983a) reported fundamental differences between the optics of the crystalline cones from the eyes of furcilia larvae of the euphausiid Thysanoessa raschii and those from the 11th stage larva of the decapod Macrobrachium rosenbergii. The refractive index distributions within the crystalline cones were directly related to the refracting and reflecting superposition optics found, respectively, in the adults of these two species. No differences, however, were found between the eyes of larval shrimps and larval crabs even though these groups use different optics as adults. All described decapod larvae have transparent apposition eyes distinguished from adult apposition eyes by the absence of distal shielding pigment between the crystalline cones. This is presumed to be an adaptation to increase camouflage in the planktonic habitat of most larval decapods. The necessary optical isolation of the ommatidia is ensured by the relatively high, constant refractive index of the crystalline cones. Within an ommatidium, axial light is transmitted to the rhabdom, whereas light from adjacent ommatidia is refracted away from the rhabdom and absorbed by the proximal shielding pigment (Nilsson, 1983a). This deflection of light in the crystalline cone of the larval eye is similar to the mechanism used in the formation of the reflecting superposition image in the adult (Fig. 1C).

The other essential feature of this type of eye is the development of a square cross section to the crystalline cone. This occurs gradually, starting at the fifth postlarval moult in Palaemonetes varians (cf. Fincham, 1980). In species where the zoeal stages complete much of their development within the egg (lecithotrophic, as opposed to planktotrophic), the development of superposition optics begins soon after hatching. These include crayfish (Hafner et al., 1982) and oplophorid shrimps (Gaten \& Herring, 1995). The development of crystalline cones that are square in cross section occurs in no species outside of the Decapoda (except for some mayflies of the family Leptophlebiidae); indeed, the presence of such a precise array of square structures is extremely rare anywhere in the animal kingdom. This sug- 
Table I. The Decapoda - classification and eye types. Only those families for which the eye type is known are listed. Ap=apposition, RS = refracting superposition, Mirror = reflecting superposition, Para = parabolic superposition. Where the eye type is in parentheses, the type is not certain; where followed by "/Ap", another worker has found apposition eyes in the same family.

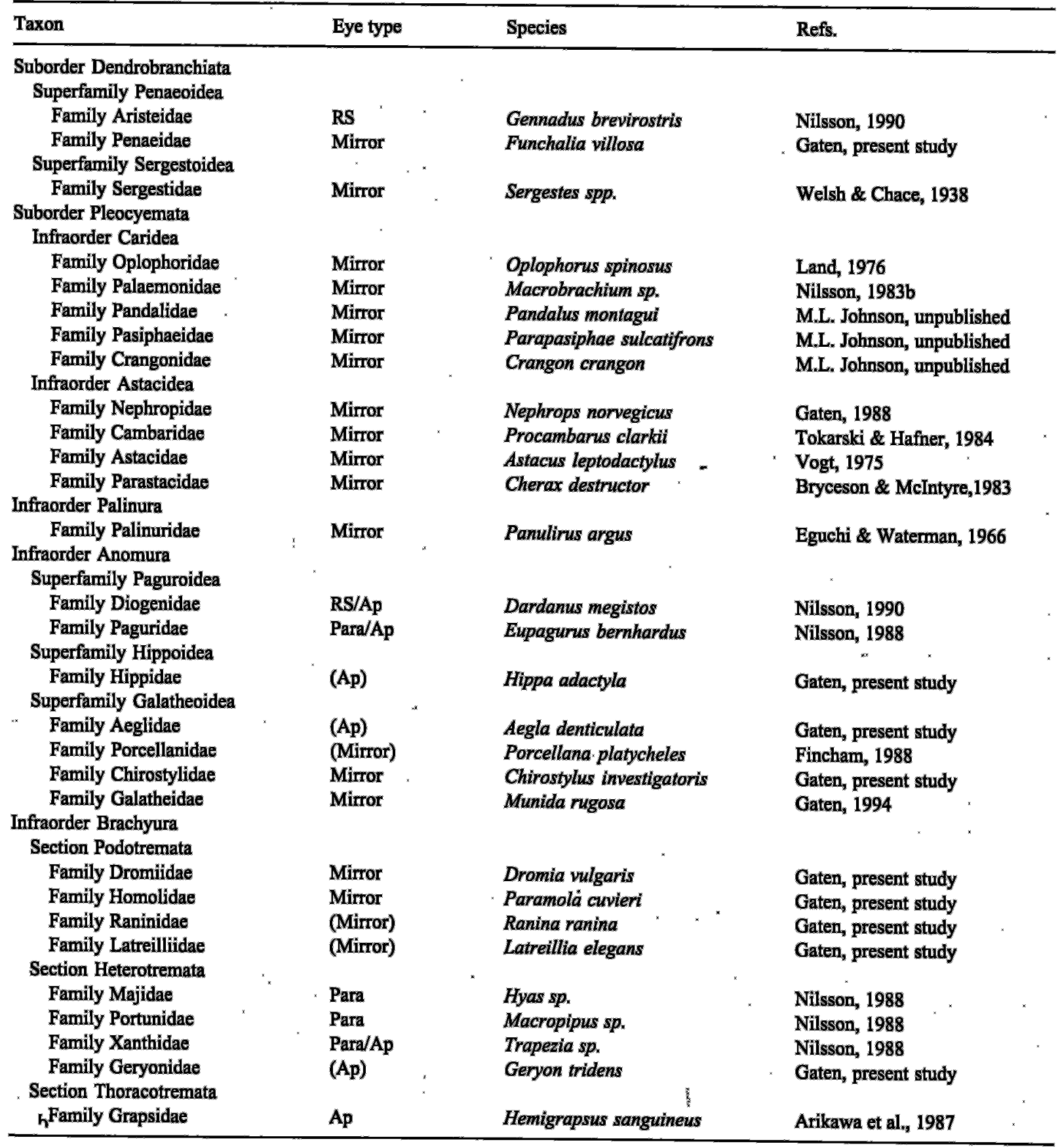

gests that, whereas the evolution of cylindrical lens systems is not an uncommon event, it may be the case that reflecting superposition optics have evolved very rarely, perhaps only once.

\section{Distribution of eye types within the Decapoda}

Apposition eyes are found in all the lower crustaceans that have compound eyes and in the lar- 
val eyes of all decapods. They clearly represent the symplesiomorphic condition, although the complex and highly-evolved apposition eyes of some crustaceans are certainly not primitive. Superposition eyes are only found in the Eumalacostraca, with only refracting superposition eyes (Syncarida - Anaspides: Peracarida - Mysidacea: Eucarida - Euphausiacea) found outside the Decapoda (Nilsson, 1989; 1990).

An examination of those members of the Decapoda in which the eye type has been determined (Table I) shows that all taxa except the Anomura and Brachyura predominantly use reflecting superposition optics. The only exception to this is the Aristeidae, which use refracting superposition optics (Nilsson, 1990). The Anomura and Brachyura both contain animals using apposition and various types of superposition optics. The Anomura have reflecting superposition eyes in the Galatheoidea (with the exception of the primitive Aeglidae) and either apposition, refracting superposition or parabolic superposition in the Paguroidea. The Hippoidea appear to use apposition optics, although in common with most burrowing forms, the eyes are small.

In the Brachyura, the Podotremata have square-faceted eyes although, prior to the present study, the optics of these eyes had not been described. Based on the examination of the eyes of three dromiid species (Dromia vulgaris, Cryptodromia canaliculata and C. granulata) and one homolid (Paramola cuvieri) there is little doubt that reflecting superposition optics are used within the Podotremata. All of these species have crystalline cones that are characteristic of this optical type, flat-sided and square in cross-section. The rhabdoms are of a typical superposition shape, although there is an additional thin distal rhabdom extending across the clear zone. The latter is especially noticeable in the large eye of Paramola cuvieri. The Heterotremata and Thoracotremata (together forming the Eubrachyura) use parabolic superposition optics in swimming crabs and those relying on concealment, whilst other species, especially shallow-water and terrestrial crabs, retain apposition optics.
Previous phylogenies based on eye structure and optics

Detailed studies of eyes and optics have been used with varying success to elucidate aspects of decapod relationships. In a study of the arrangement and connections of the optic neuropiles, Elofsson \& Dahl (1970) showed fundamental differences between the malacostracan and nonmalacostracan eye. Work on the photoreceptive organs (including nauplius eyes) of lower crustaceans has been used as evidence for four higher groupings of Crustacea: Malacostraca, Anostraca, Phyllopoda and Maxillopoda/Ostracoda (Elofsson, 1966). Dahl (1963) reviewed compound eye structure with respect to the evolution of recent Crustacea. Based on a then comprehensive list of compound eye descriptions, including both insects and crustaceans, Paulus (1979) argued in favour of the monophyletic origin of the Arthropoda.

The discovery of a unique form of optics in decapod crustaceans, termed reflecting superposition (Vogt, 1975), prompted a number of authors to consider the relationships within the order in the light of this discovery. Land (1981) came to the conclusion that Euphausiidae were more closely related to the Mysidae than to the Decapoda, based on the refracting superposition optics shared by these groups, and suggested that the superorder Eucarida was unsound. He also grouped together the long-bodied decapods and the galatheid anomurans as they were thought to be the only taxa sharing reflecting superposition eyes. He concluded that eye design constituted a conservative character, providing a good indication of evolutionary origins. Fincham (1980) came, independently, to much the same conclusions, but also included the Dromioidea and Homoloidea with the galatheids and long-bodied forms as these groups also have square-faceted eyes. The remaining taxa, Brachyura, Hippoidea and Paguroidea formed a second group, as they were then assumed to retain apposition eyes throughout their adult life. These ideas were supported in general by Cronin (1986). All of the conclusions arrived at in these papers seemed to be reasonable, defining the cladistic proximity of 
the groups based on observed synapomorphies. The subsequent descriptions of refracting superposition eyes from à variety of crustacean taxa (Nilsson, 1990), however, cast considerable doubt on the description of refracting superposition eyes as synapomorphic.

Further doubt on the use of optical types in phylogeny arose with the discovery that larval decapod eyes are pre-adapted for the formation of reflecting superposition eyes (Nilsson, 1983a). As described above, the larval eye provides the functional basis for the reflecting mechanism as a biproduct of maintaining optical isolation of the ommatidia in the transparent apposition eye. As all decapod eyes appear to be pre-adapted in this way, Nilsson (1983a) suggested that reflecting superposition optics may have arisen more than once.

\section{Discussion}

The use of descriptions of eye structure and optics may be of help in constructing decapod phylogenies as long as attention is paid to the restrictions alluded to above. If the stratigraphic ranges of the extant decapod crustaceans (excluding those with reduced or absent eyes) is combined with the known optical types, a number of patterns are apparent (Fig. 2). The extant Penaeidea, Caridea, Palinura and Astacidea all possess reflecting superposition eyes. These groups (with the possible exception of the Penaeidea) probably arose from an explosive radiation in the Devonian and Carboniferous (Hessler, 1983) from an ancestor that may have possessed reflecting superposition eyes. Although reflecting optics could have evolved independently in each of these taxa, there is no evidence to suggest that this was the case. If it is assumed that this state was common to all of the early Decapoda, it is only necessary to suggest that these unusual optics evolved once from the apposition eyes of the ancestral eumalacostracan. Accurate descriptions of the facet patterns in fossil decapod eyes may well provide an answer to this question.

The only long-bodied decapods using superposition optics that are not of the reflecting type are the penaeid shrimps of the family Aristeidae. These use refracting superposition optics, although in some species many of the crystalline cones are squarish in cross-section and are packed in a square array over more than one third of the eye (Nilsson, 1990). This could indicate that these shrimps are changing from refracting to reflecting optics, although the mechanism for such a change is unknown. In addition, there is no known advantage in possessing refracting rather than reflecting superposition optics in terms of either sensitivity or resolution. The situation seen in the Aristeidae may indicate a less direct transformation. Other shrimps moving into deep seas, such as the oplophorid Hymenodora glacialis, have abandoned reflecting superposition optics altogether, filling the whole eye with hypertrophied rhabdoms instead (Welsh \& Chase, 1937). Similarly, bresiliid shrimps have lost the crystalline cone layer found in the eyes of related shrimps, although the ommatidia still show signs of being arranged in a square array, especially during the postlarval stages (Gaten et al., 1998). If the Aristeidae had abandoned reflecting optics after assuming a deep-sea existence and subsequently moved back to a brighter habitat, they would then need to evolve a suitable optical arrangement. The evolution of graded-index crystalline cones, rather than crystalline cones with a square cross-section, would now result in refracting superposition optics (Nilsson, 1990).

In contrast to the relative predictability of the long-bodied decapods, the Anomura and Brachyura include species using apposition optics and all three types of superposition optics. The situation is further confused by the variety of specialised habitats occupied by the adults of these infraorders, often resulting in convergent evolution. Deep-sea forms such as the Homolodromiidae, Homolidae, Latreillidae, Cymonomidae, and some Majidae, Xanthidae and Portunidae, are thought to show signs of regressive evolution brought about by the uniform conditions of this habitat. These adaptations are said to include unrolling of the abdomen, reduction of the eyes and the weakening of the locomotor system (Števčić, 1971). Similarly, regressive evolution may occur in burrowing species (such as the brachyurans 
Ranina and Corystes, and the anomurans Hippa and Albunea), again leading to a reduction of the eyes. According to Fincham (1980) burrowing members of the superfamily Thalassinoidea also have small, hexagonally-faceted eyes. In species from such stable environments, especially the deep seas, it is often particularly difficult to distinguish adaptive from ancestral features. Some taxa exhibit a progressive loss of optical function with depth, as seen in the galatheid genus Munidopsis (Zharkova, 1975) and in the brachyuran Cymonomus (Rice, 1990).

Within the Anomura, there is a distinction between the Galatheoidea, which mainly have square facets and use reflecting optics, and the Paguroidea (and probably the Hippoidea), which do not. Reflecting superposition optics are used within the Galatheidae (Gaten, 1994), although the eyes differ somewhat from those of the longbodied decapods because they use a rhabdomeric light guide to channel axial light from the crystalline cones to the rhabdom layer (Gaten, 1990). Based only on an external examination, the eyes of Chirostylidae also appear to use reflecting optics (unpublished observations). The situation in the Porcellanidae is not quite so clear. Although much of the eye is covered with square facets, the crystalline cones are frequently rounded at the comers, leading Fincham (1988) to conclude that reflecting superposition optics could only be used over part of the eye. It may be that porcellanid eyes are in the process of developing, or losing, this type of optics. The Aeglidae are the most primitive galatheoids (Martin \& Abele, ! 1986) and are the only galatheoids having hexagonally-faceted eyes. They are also the only anomurans endemic to South America and the only freshwater representatives of the infraorder. In view of the isolated position of this group (both biogeographically and ecologically) it is not easy to explain the evolution of aeglid optics. However, they may have evolved from a terrestrial ancestor (Martin \& Abele, 1986) and the loss of reflecting superposition optics, if they ever possessed them, may have been concerned with this stage in their evolution. As no crustacean with this type of eye has made the transition to a terrestrial way of life it may be that the neotenic retention of the larval apposition eye was necessary before this habitat could be exploited.

None of the Paguroidea possess square-faceted eyes. Some Paguridae have parabolic superposition eyes (Nilsson, 1988), whereas refracting superposition eyes have been described from two species of Diogenidae (Nilsson, 1990) and most of the smaller hermit crabs of both families have apposition eyes. It is proposed here that the Paguroidea arose from square-faceted ancestors, probably evolving apposition eyes initially. This evolution from using superposition optics to using apposition optics would be the reverse of the usual situation where animals with superposition optics evolve from the plesiomorphic apposition state. Migration of an ancestor with superposition eyes into a bright habitat would not necessarily lead to the abandonment of superposition optics. Some day-flying insects have superposition eyes that approach the theoretical limit of resolution for compound eyes (Land, 1984). It is also unlikely that each step in the evolution of the superposition eye could be reversed in such a way that a typical apposition eye would be the end product. For these reasons, it is assumed that the apposition eye found in some pagurids is the result of progenetic paedomorphosis, with the apposition optics found in the larvae retained in the adults. Paedomorphosis is probably a common occurrence in the unstable inshore environment and has been implicated in the evolution of many crustacean orders (Schram, 1982). Subsequent movement of the adults to deeper water, or a darker habitat, would inevitably lead to the evolution of a more sensitive eye. It might be expected that reflecting superposition optics would evolve as the larval decapod eye is preadapted for the evolution of this type of eye. However, as only parabolic and refracting superposition eyes are found in this group, this may be indicative that optics of these types evolve more readily than that found in reflecting superposition eyes.

The Brachyura may be divided into groups following two optical strategies along much the same lines as the Anomura. The primitive crabs within the families Dromiidae and Homolidae (and probably Raninidae and Latreilliidae) all have square-faceted eyes and crystalline cones 


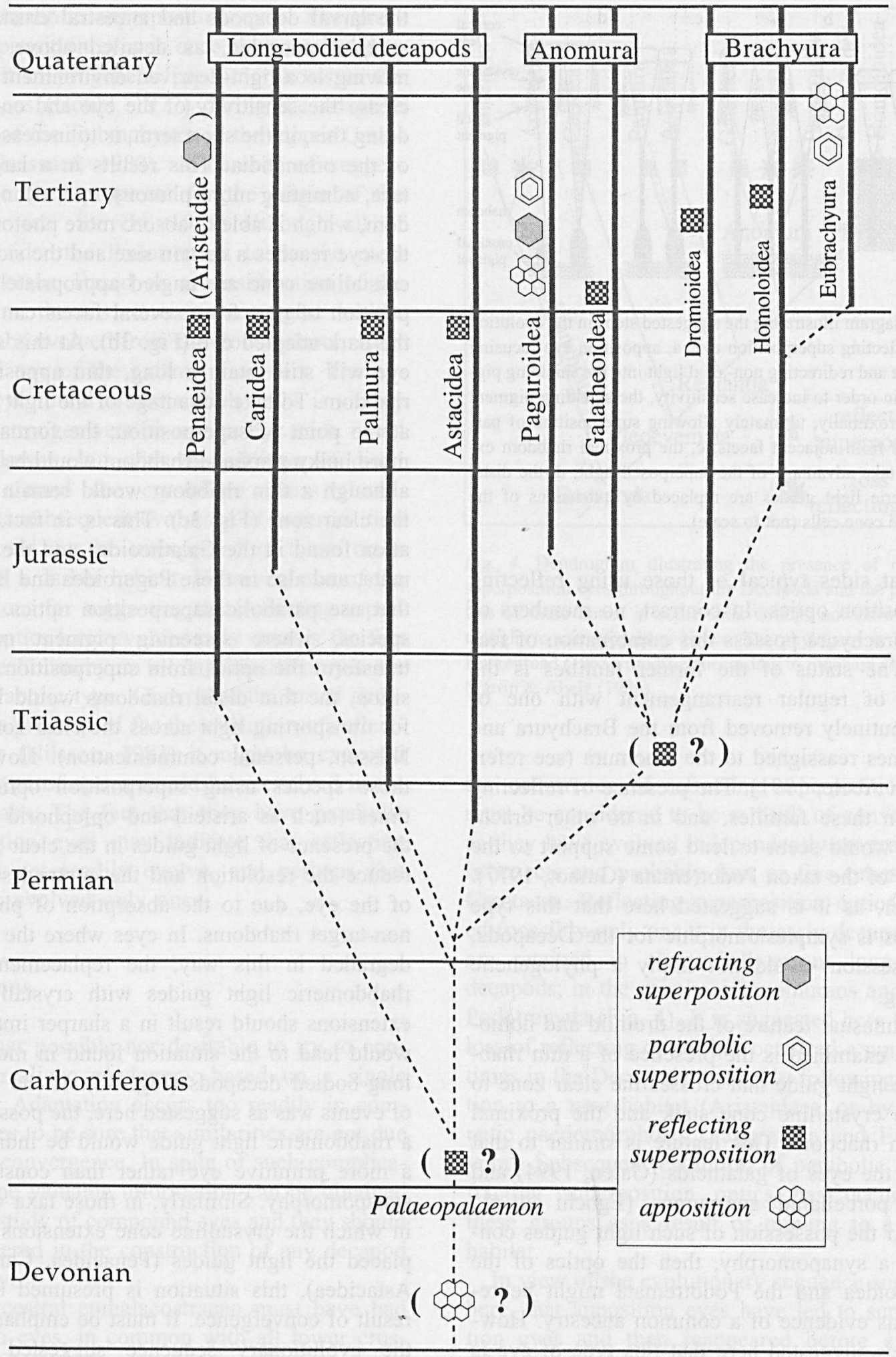

Fig. 2. The stratigraphic ranges of the extant crustaceans (excluding those with reduced or absent eyes) together with the optics used (in parentheses where presumed). The dotted lines indicate possible evolutionary relationships (based on Schram, 1982; Wägele, 1989; Glaessner, 1969). 


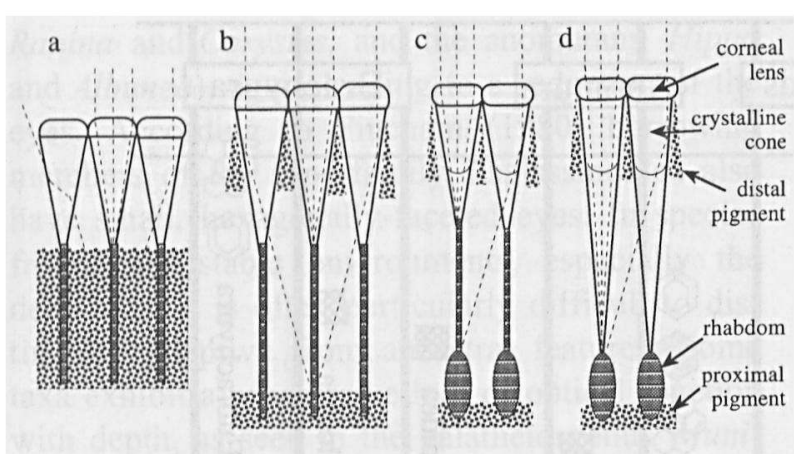

Fig. 3. Diagram illustrating the suggested steps in the evolution of the reflecting superposition eye: a, apposition eye focusing axial light and redirecting non-axial light into the shielding pigment; $b$, in order to increase sensitivity, the shielding pigment retreats proximally, ultimately allowing superposition of paraxial rays from adjacent facets; $c$, the proximal rhabdom expands to take advantage of the superposed light; $\mathrm{d}$, the distal rhabdomeric light guides are replaced by extensions of the crystalline cone cells (not to scale).

with flat sides typical of those using reflecting superposition optics. In contrast, no members of the Eubrachyura possess this combination of features. The status of the former families is the subject of regular rearrangement with one or more routinely removed from the Brachyura and sometimes reassigned to the Anomura (see references in Abele, 1991). The presence of reflecting optics in these families, and in no other brachyurans, would seem to lend some support to the concept of the taxon Podotremata (Guinot, 1977). However, as it is suggested here that this type of optics is symplesiomorphic for the Decapoda, its possession would not imply a phylogenetic grouping.

One unusual feature of the dromiid and homolid eyes examined is the presence of a thin rhabdomeric light guide that crosses the clear zone to link the crystalline cone stalk and the proximal fusiform rhabdom. This feature is similar to that seen in the eyes of galatheids (Gaten, 1994) and in the porcellanid anomurans (Eguchi et al., 1982). If the possession of such light guides constituted a synapomorphy, then the optics of the Galatheoidea and the Podotremata might be regarded as evidence of a common ancestry. However, it is suggested here that this type of eye is of a more primitive design than that seen in other decapods. The apposition eye (Fig. 3a) found in the larval decapods and ancestral crustaceans is symplesiomorphic, as detailed above. Animals moving to a light-deprived environment must increase the sensitivity of the eye and one way of doing this, in the short term, is to increase the size of the ommatidia. This results in a larger aperture, admitting more photons, and a longer rhabdom, which is able to absorb more photons. When the eye reaches a certain size and the sides of the crystalline cone are angled appropriately, superposition of rays from several facets can occur in the dark-adapted eye (Fig. 3b). At this stage, the eye will still retain a long, thin apposition-type rhabdom. To take advantage of the light available at the point of superposition, the formation of a more bulky proximal rhabdom would be expected although a thin rhabdom would remain crossing the clear zone (Fig. 3c). This is, in fact, the situation found in the Galatheoidea and the Podotremata, and also in those Paguroidea and Brachyura that use parabolic superposition optics. In those species, where screening pigment migrations transform the optics from superposition to apposition, the thin distal rhabdoms would be useful for transporting light across the clear zone (D.-E. Nilsson, personal communication). However, in those species using superposition optics at all times (such as aristeid and oplophorid shrimps) the presence of light guides in the clear zone will reduce the resolution and the contrast sensitivity of the eye, due to the absorption of photons by non-target rhabdoms. In eyes where the image is degraded in this way, the replacement of the rhabdomeric light guides with crystalline cone extensions should result in a sharper image. This would lead to the situation found in most of the long-bodied decapods (Fig. 3d). If the sequence of events was as suggested here, the possession of a rhabdomeric light guide would be indicative of a more primitive eye rather than constituting a synapomorphy. Similarly, in those taxa with eyes in which the crystalline cone extensions have replaced the light guides (Penaeidea, Caridea and Astacidea), this situation is presumed to be the result of convergence. It must be emphasised that the evolutionary sequence suggested here is largely speculative.

The remaining Brachyura possess apposition 
eyes or parabolic superposition eyes. The presence of apposition eyes is once again assumed to be a result of progenetic paedomorphosis in the shallow seas (Gould, 1977) during the adaptive radiation of the Eubrachyura in the Upper Cretaceous (Glaessner, 1980). A number of suggestions have been proposed for the origin of the Brachyura (see Števčić, 1971) although all of these consider the Podotremata to be the most primitive crabs. Based on a consideration of the optics alone, there is no reason to suggest that the higher crabs evolved from the Podotremata rather than from any of the extant infraorders. The apposition eye found in some adult crabs is simply a larger, stronger version of the eye seen in all decapod larvae, but with the addition of distal pigment around the crystalline cones (Land, 1981). The subsequent evolution of superposition optics would not be unexpected in those crabs moving to a darker habitat. However, one of the main reasons for suggesting that reflecting superposition optics have evolved only once is the fact that in the Eubrachyura all superposition eyes are of the parabolic type. Given that the larval decapod eye is preadapted for the evolution of reflecting optics (Nilsson, 1983) it might be expected that this type of optics would have evolved in the higher crabs. The fact that they have parabolic superposition eyes may indicate that reflecting optics do not readily evolve, and perhaps that they have evolved only once.

\section{Conclusions}

It is neither possible nor desirable to try to construct a realistic phylogeny based on a single character. Adaptation occurs too readily in compound eyes to be sure that similarities are not due solely to convergence. In spite of such complications, some valuable information can be obtained from the study of compound eyes and they should be considered in the construction of any decapod phylogeny.

The ancestral eumalacostracan must have had apposition eyes, in common with all lower crustaceans. As apposition eyes also occur as a result of heterochrony, their presence in any taxon can have little phylogenetic significance. Similarly,

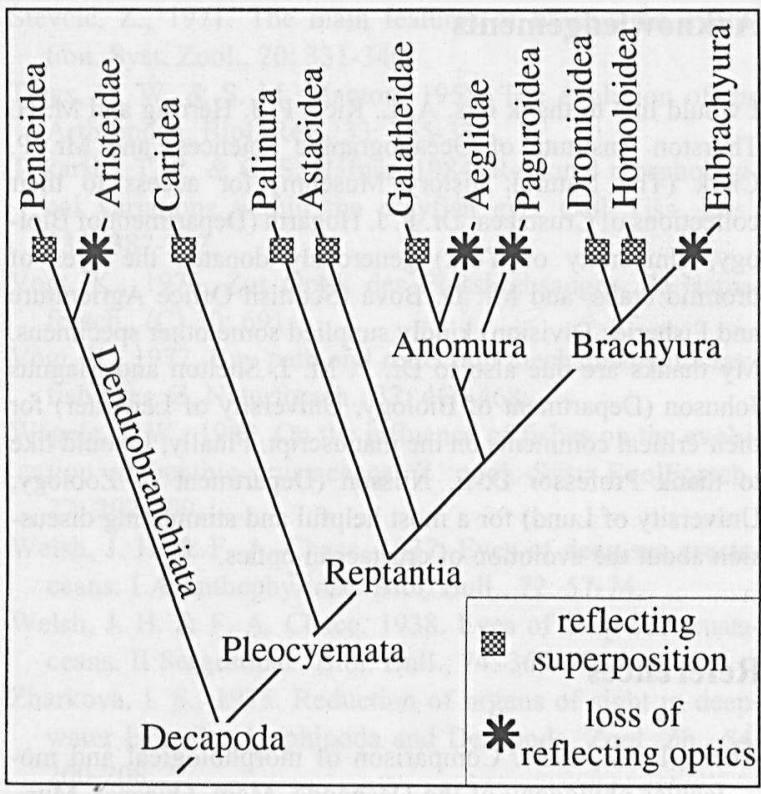

Fig. 4. Dendrogram illustrating the presence of reflecting superposition eyes throughout the Decapoda and the presumed loss of these optics in some taxa. Groups not shown are all thought to use apposition optics. The phylogeny is based on Burkenroad (1963), modified according to Fincham (1980) and Martin \& Abele (1986).

the occurrence of refracting superposition eyes must be considered to be a result of convergence as they have evolved independently several times in insects and probably four or five times in the Crustacea. Reflecting superposition optics evolved (possibly only once) in the early decapods and are retained in almost all extant long-bodied decapods, in the galatheoid anomurans and in the Podotremata (Fig. 4). It is suggested here that the loss of reflecting optics has occurred a number of times in the Decapoda, probably following migration to a new habitat (Aristeidae), or by progenetic paedomorphosis (Paguroidea and Eubrachyura). Subsequent evolution of parabolic and refracting superposition optics has occurred in these groups as a result of moving to a darker habitat.

In view of the evolutionary sequence suggested here, that apposition eyes have led to superposition eyes and then reappeared before evolving into other types of superposition eyes, the inevitable conclusion is that the study of optics alone will solve very few phylogenetic problems. 


\section{Acknowledgements}

I would like to thank Drs. A. L. Rice, P. J. Herring and M. H. Thurston (Institute of Oceanographic Sciences) and Mr. P. Clark (The Natural History Museum) for access to their collections of Crustacea. Dr. P. J. Hogarth (Department of Biology, University of York) generously donated the eyes of dromiid crabs, and Mr. D. Bova (Scottish Office Agriculture and Fisheries Division) kindly supplied some other specimens. My thanks are due also to Dr. P. M. J. Shelton and Magnus Johnson (Department of Biology, University of Leicester) for their critical comments on the manuscript. Finally, I would like to thank Professor D.-E. Nilsson (Department of Zoology, University of Lund) for a most helpful and stimulating discussion about the evolution of crustacean optics.

\section{References}

Abele, L. G., 1991. Comparison of morphological and molecular phylogeny of the Decapoda. Mem. Queensl. Mus., 31: 101-108.

Arikawa, K., K. Kawamata, T. Suzuki \& E. Eguchi, 1987. Daily changes of structure, function and rhodopsin content in the compound eye of the crab Hemigrapsus sanguineus. J. comp. Physiol., (A) 161: 161-174.

Bryceson, K. P. \& P. McIntyre, 1983. Image quality and acceptance angle in a reflecting superposition eye. J. comp. Physiol., (A) 151: 367-380.

Burkenroad, M. D., 1963. The evolution of the Eucarida, (Crustacea, Eumalacostraca), in relation to the fossil record. Tulane Stud. Geol., 2: 1-17.

Clarkson, E. N. K. \& R. Levi-Setti, 1975. Trilobite eyes and the optics of Des Cartes and Huygens. Nature, 254: 663667.

Cronin, T. W., 1986. Optical design and evolutionary adaptation in crustacean compound eyes. J. crust. Biol., 6: 123.

Dahl, E., 1963. Main evolutionary lines among Recent Crustacea. In: H. B. Whittington \& W. D. I. Rolfe (eds.), Phylogeny and evolution of Crustacea: 1-14 (Mus. Comp. Zool., Cambridge).

Eguchi, E. \& T. H. Waterman, 1966. Fine structure patterns in crustacean rhabdoms. In: C. G. Bernhard (ed.), The functional organisation of the compound eye: 105-124 (Pergamon Press, Oxford).

Eguchi, E,, T. Goto \& T. H. Waterman, 1982. Unorthodox pattern of microvilli and intercellular junctions in regular retinular cells of the porcellanid crab Petrolisthes. Cell Tiss. Res., 222: 493-513.

Elofsson, R., 1966. The nauplius eye and frontal organs in Crustacea. Morphology, ontogeny and fine structure: 1-23 (Zool. Inst., Lund).

Elofsson, R. \& E. Dahl, 1970. The optic neuropiles and chiasmata of Crustacea. Z. Zellforsch., 107: 343-360.

Exner, S., 1891. Die Physiologie der facettierten Augen von Krebsen und Insecten: 1-206 (Franz Deuticke, Leipzig).
Fincham, A. A., 1980. Eyes and classification of malacostracan crustaceans. Nature, 287: 729-731.

Fincham, A. A., 1988. Ontogeny of anomuran eyes. Symp. Zool. Soc., 59: 123-155.

Gaten, E., 1988. Light-induced damage to the dioptric apparatus in Nephrops norvegicus and the quantitative assessment of the damage. Mar. Behav. Physiol, 13: 169-183.

Gaten, E., 1990. The ultrastructure of the compound eye of Munida rugosa (Crustacea: Anomura) and pigment migration during light and dark adaptation. J. Morphol, 205: 243-253.

Gaten, E., 1994. Geometrical optics of a galatheid compound eye. J. comp. Physiol., (A) 175: 749-759.

Gaten, E. \& P. J. Herring, 1995. The morphology of the reflecting superposition eyes of larval oplophorid shrimps. J. Morphol., 255: 19-29.

Gaten, E., P. J. Herring, P. M. J. Shelton.\& M. L. Johnson, 1998. Comparative morphology of the eyes of postlarval bresiliid shrimps obtained from the region of hydrothermal vents. Biol. Bull. In press.

Glaessner, M. F., 1969. Decapoda. In: R. C. Moore (ed), Treatise on invertebrate paleontology: 339-533 (Kansas Univ. Press, Lawrence).

Glaessner, M. F., 1980. New Cretaceous and Tertiary crabs (Crustacea: Brachyura) from Australia and New Zealand. Trans. Roy. Soc. South Aust., 104: 171-192.

Gould, S. J., 1977. Ontogeny and phylogeny: 1-501 (Belknap Press, Cambridge, Mass).

Guinot, D., 1977. Zoologie. Propositions pour une nouvelle classification des Crustacés Décapodes Brachyoures. C. $\mathbf{r}$. hebd. Séanc. Acad. Sci., Paris, (D) 285: 1049-1052.

Hafner, G. S., T. Tokarski \& G. Hammond-Soltis, 1982. Development of the crayfish retina: A light and electron microscopic study. J. Morphol, 173: 101-118.

Hessler, R. R., 1983, A defence of the caridoid facies: wherein the early evolution of the Eumalacostraca is discussed. Crust. Issues, 1: 145-164.

Kunze, P., 1979, Apposition and superposition eyes. In: H. Autrum (ed), Handbook of sensory physiology: 441-502 (Springer Verlag, Berlin).

Land, M. F., 1976. Superposition images are formed by reflection in the eyes of some oceanic decapod Crustacea. Nature, 263: 764-765.

Land, M. F., 1981. Optical mechanisms in the higher Crustacea with a comment on their evolutionary origins. In: $\mathbf{M}$. S. Laverack \& D. J. Cosens (eds.), Sense organs: 31-48 (Blackie, London).

Land, M. F., 1984. The resolving power of diumal superposition eyes measured with an ophthalmoscope. J. comp. Physiol., (A) 154: 515-533.

Martin, J. W. \& L. G. Abele, 1986. Phylogenetic relationships of the genus Aegla (Decapoda: Anomura: Aeglidae), with comments on anomuran phylogeny. J. crust. Bìol, 6: 576-616.

Nilsson, D.-E., 1983a. Evolutionary links between apposition and superposition optics in crustacean eyes. Nature, 302: 818-821.

Nilsson, D.-E., 1983b. Refractive index gradients subserve 
optical isolation in a light-adapted reflecting superposition eye. J. exp. Zool., 225: 161-165.

Nilsson, D.-E., 1988. A new type of imaging optics in compound eyes. Nature, 332: 76-78.

Nilsson, D.-E., 1989. Optics and evolution of the compound eye. In: R. C. Hardie \& D. G. Stavenga (eds.), Facets of vision: 30-73 (Springer Verlag, Berlin).

Nilsson, D.-E., 1990. Three unexpected cases of refracting superposition eyes in crustaceans. J. comp. Physiol., (A) 167: 71-78.

Paulus, H. F., 1979. Eye structure and the monophyly of the Arthropoda. In: A. P. Gupta (ed.), Arthropod phylogeny: 299-383 (Van Nostrand Reinhold, New York).

Ríce, A. L., 1990. The nomenclature of crabs collected during the cruises of HMS Porcupine in 1869 and 1870. Bull. Br. Mus. nat. Hist., 18: 1-23.

Schram, F. R., 1982. The fossil record and evolution of Crustacea. In : L. G. Abele (ed.), The biology of Crustacea: 93147 (Academic Press, New York).

Shelton, P. M. J., E. Gaten \& P. J. Herring, 1992. Adaptations of tapeta in the eyes of mesopelagic decapod shrimps to match the oceanic irradiance distribution. J. mar. Biol. Assoc. U.K., 72: 77-88.
Števčič, Z., 1971. The main features of brachyuran evolution. Syst. Zool., 20: 331-340.

Tiegs, O. W. \& S. M. Manton, 1958. The evolution of the Arthropoda. Biol. Rev., 33: 255-337.

Tokarski, T. R. \& G. S. Hafner, 1984، Regional morphological variations within the crayfish eye. Cell Tiss. Res., 235: 387-392.

Vogt, K., 1975. Zur Optik des Flusskrebsauges. Z. Naturforsch., (C) 30: 691.

Vogt, K., 1977. Ray path and reflection mechanisms in crayfish eyes, Z. Naturforsch., 32: 466-468.

Wãgele, J. W., 1989. On the influence of fishes on the evolution of benthic crustaceans. Z. zool. Syst. EvolForsch., 27: 297-309.

Welsh, J. H. \& F. A. Chace, 1937. Eyes of deep-sea crustaceans. I Acanthephyridae. Biol. Bull, 72: 57-74.

Welsh, J. H. \& F. A. Chace, 1938. Eyes of deep-sea crustaceans. II Sergestidae. Biol. Bull, 74: 364-375.

Zharkova, I. S., 1975. Reduction of organs of sight in deepwater Isopoda, Amphipoda and Decapoda. Zool. Zh., 54: 200-208.

Received: 2 February 1998 